\title{
Turning bad into good: How resilience resources protect organizations from demanding work environments
}

Andrea Ceschi, PhDFranco Fraccaroli, Arianna CostantiniDr., and Riccardo Sartori, PhD

\section{QUERY SHEET}

This page lists questions we have about your paper. The numbers displayed at left can be found in the text of the paper for reference. In addition, please review your paper as a whole for correctness.

Q1: Au: Please provide missing affiliation (Department, City, State/Country).

Q2: Au: Please provide complete postal address.

Q3: $\mathrm{Au}$ : Bandura - Please provide the correct text citation, page for the quote, and the complete reference.

Q4: Au: Please provide reference for citation [Ortiz-de-Mandojana \& Bansal, 2015].

Q5: Au: Please provide reference for citation [Ortiz-de-Mandojana \& Bansal, 2015].

Q6: Au: Please specify [Xanthopoulou et al., 2009] denotes [Xanthopoulou et al., 2009a] or [Xanthopoulou et al., 2009b].

Q7: Au: Please provide reference for citation [Van Yperen \& Snijders, 2000].

Q8: Au: Please provide reference for citation [Luthans, Youssef, \& Avolio, 2007].

Q9: Au: Please provide reference for citation [Hobfoll, 1989].

Q10: Au: Please provide reference for citation [Hobfoll, 2002].

Q11: Au: Please provide reference for citation [Hobfoll, 2011].

Q12: Au: Please provide reference for citation [Meneghel, Martìnez, \& Salanova, 2016].

Q13: Au: Please provide reference for citation [Ortiz-de-Mandojana \& Bansal, 2015].

Q14: Au: Please provide reference for citation [Laschinger, Wong, Cummings, \& Grau, 2014].

Q15: Au: Please provide reference for citation [Judge et al., 2000].

Q16: Au: Please provide reference for citation [Bakker et al., 2014].

Q17: Au: Please provide reference for citation [Van Veldhoven \& Meijman, 1994].

Q18: $\mathrm{Au}$ : CFAs - please spell out

Q19: Au: PROCESS - please define this

Q20: $\mathrm{Au}: \mathrm{B}$ - is this the unstandardized or standardized beta

Q21: $\mathrm{Au}: \mathrm{B}$ - is this the unstandardized or standardized beta

Q22: Au: Please provide reference for citation [King, Newman, \& Luthans, 2015].

Q23: Au: Please specify [Xanthopoulou et al., 2009] denotes [Xanthopoulou et al., 2009a] or [Xanthopoulou et al., 2009b].

Q24: $\mathrm{Au}$ : Please provide reference for citation [Ortiz-de-Mandojana \& Bansal, 2015].

Q25: Au: CILS, CGIL, UIL - please spell out

Q26: Au: Please cite [Bakker \& Demerouti, 2014] in text or delete reference.

Q27: Au: Buruck et al. 2016 - please provide the missing page range

Q28: Au: Cheung et al. 2011 - please provide the missing page range

Q29: Au: Please provide editor name and page range [Demerouti \& Bakker, 2008]. 
Q30: Au: Please provide volume number for the reference [Gilbert, Foulk, \& Bono, 2017].

Q31: Au: Please provide city name and location AND the month of presentation for the reference [Ho, Teo, Bentley, Verreyne, \& Galvin, 2014].

Q32: Au: Please cite [King, Newman, \& Luthans, 2016] in text or delete reference.

Q33: Au: Please cite [Laschinger \& Fida, 2014] in text or delete reference.

Q34: Au: Please cite [Meneghel, Salanova, \& Martínez, 2016] in text or delete reference.

Q35: Au: Please cite [Merrick, Volpe-Vartanian, Horgan, \& McCann, 2007] in text or delete reference.

Q36: Au: Please provide editor name and city name for the reference [Mitamura, Reuman, \& Tugade, 2014].

Q37: Au: Please cite [Ortiz-de-Mandojana \& Bansal, 2016] in text or delete reference.

Q38: Au: Rees et al. 2015 - please provide the missing page range

Q39: Au: Please provide volume number for the reference [Schaufeli \& Taris, 2014].

Q40: Au: Please provide city name for the reference [Shiller, 2012].

Q41: Au: Please UnSuperScript the $s^{*}$ in the note, remove the space between each ${ }^{*}$ each $\mathrm{p}$ and change th eperiod after .05 to a comma and resubmit a corrected figure.

\section{TABLE OF CONTENTS LISTING}

The table of contents for the journal will list your paper exactly as it appears below:

Turning bad into good: How resilience resources protect organizations from demanding work environments Andrea Ceschi, PhDFranco Fraccaroli, Arianna CostantiniDr., and Riccardo Sartori, PhD 


\title{
Turning bad into good: How resilience resources protect organizations from demanding work environments
}

\author{
Andrea Ceschi, PhD ${ }^{\mathrm{a}}$ (D), Franco Fraccaroli ${ }^{\mathrm{b}}$, Dr. Arianna Costantini ${ }^{\mathrm{a}}$ \\ and Riccardo Sartori, $\mathrm{PhD}^{\mathrm{a}}$
}

${ }^{a}$ Department of Human Sciences, Verona University, Verona, Italy; bUniversity of Trento

\begin{abstract}
An organization's survival and its performance are often connected to employees' well-being, which in intensive work conditions can be compromised by employee exhaustion. To date, the last economic crisis has forced several companies to downsize and leave the remaining employees facing higher job demands and vulnerability toward job exhaustion. The present study investigates whether resilience together with other personal resources can function as a psychological shield through a mediation and/or moderation process that mitigate the emergence of burnout. Based on a sample of employees from three different Italian companies $(N=208)$, our results confirmed that "resilience resources" (i.e., resilience, self-efficacy, self-regulation) mediated the relationship between job demands, exhaustion, and task performance (i.e., energetic process). These results suggest that organizational environments characterized by challenging demands are likely to foster the development of resilience resources to cope with the emergence of potentially harming processes.
\end{abstract}

\section{ARTICLE HISTORY}

Received 29 June 2017

Accepted 22 September 2017

\section{KEYWORDS}

Energetic process; job demands; organizational resilience; personal resources; task performance

In order to succeed, people need a sense of self-efficacy, to struggle together with

In the industrial and organizational $(\mathrm{I} / \mathrm{O})$ research domain, the construct of resilience is experiencing renewed interest as the result of recent global events (e.g., subprime mortgage crisis, government debt, automotive industry crisis), which have negatively affected many companies and corporations (Orchiston, Prayag, \& Brown, 2016; Ortiz-de-Mandojana \& Bansal, 2015). Organizational resilience is defined as the company's ability to absorb shocks caused by unpredictable events, the capacity to generate a specific response to them, and capitalizing on experiences that can ensure the survival of the organization (Limnios, Mazzarol, Ghadouani, \& Schilizzi, 2014).

Many of the recent problems faced by several organizations are connected with the financial crisis of 2008 and its subsequent effects on companies. These problems began with the failures of certain financial institutions from 
the United States and then grew into a global crisis that extended to Europe too, with a significant reduction of the global market value of goods and activities (Shiller, 2012). The decline of organizations' activities generates a progressive reduction of the work force within them, necessitating the remaining employees to adapt to new work conditions (Chodorow-Reich, 2014). Employees of downsized companies often have to face higher job demands, which results in more vulnerability to burnout. Such a psychological condition is the result of the strain-stress process at work, known also as "energetic process," in which intensive job demands can cause employees' exhaustion and ultimately affect job performance (Balducci, Schaufeli, \& Fraccaroli, 2011).

Although the relationship between employee exhaustion, well-being, and job performance has been the subject of extensive research (e.g., Bakker, Demerouti, Taris, Schaufeli, \& Schreurs, 2003; Hakanen, Bakker, \& Schaufeli, 2006; Lorens, Bakker, Schaufeli, \& Salanova, 2006; Schaufeli \& Bakker, 2004), current work environment conditions prompt a renewed interest in the energetic process and in the study of how psychological constructs are able to reduce or buffer it (Brauchli, Schaufeli, Jenny, Füllemann, \& Bauer, 2013; Hakanen, Schaufeli, \& Ahola, 2008; Nahrgang, Morgeson, \& Hofmann, 2011; Schaufeli, Bakker, \& Van Rhenen, 2009; Schaufeli \& Taris, 2014). Constructs that come from the classic definition of personal resources such as optimism, self-efficacy, and self-regulation or from the construct of psychological capital, such as resilience, are protective factors that deter the emergence of exhaustion and facilitate better job performance (Bakker et al., 2010; Xanthopoulou, Bakker, Demerouti, \& Schaufeli, 2009a, 2009b). However, to the best of our knowledge, little is known about mechanisms of their function, in mediating and/or moderating the energetic process (Cheung, Tang, \& Tang, 2011; Schaufeli \& Taris, 2014; Van den Heuvel et al., 2010).

More research is needed to identify the role of personal resources and of resilience within such a relationship to deepen our understanding of how potentially harming organizational conditions can lead to the development of employees' resources. Moreover, given that current organizational contexts are dynamic and the capacity to anticipate and adjust to the environment is vital, the importance of more extensively investigating the effects of stress adaptability (i.e., organizational resilience; see Ho, Teo, Bentley, Verreyne, \& Galvin, 2014; Orchiston et al., 2016; Ortiz-de-Mandojana \& Bansal, 2015) on employees' outcomes becomes clear. Although such a construct can be interpreted as an organization asset, it builds on the individuals who compose the organization itself, and by developing employees' resilience the organization will become more adaptive and successful over time (Youssef \& Luthans, 2005).

Against this background, building upon findings from research in the organization psychology domain, resilience as well as other personal resources seem to function as deterrents toward the negative outcomes of the energetic 
process, acting as classic moderators between job stressors and the emergence of exhaustion (Meyers, van Woerkom, \& Bakker, 2013). On the other hand, they could also be conceived as a mediator of such a relationship. Specifically, an intensive (yet challenging) work environment may enhance resilience and resources such as self-efficacy to cope with higher job demands. This reasoning is in line with the idea that resilience development seems to depend on contexts of significant adversity (Ablett \& Jones, 2007). Accordingly to Bandura (1982), individuals with high levels of resilience and self-efficacy would easily adapt, thanks to the development of coping strategies and by converting stressful factors into learning opportunities.

Before examining the mediating and moderating roles of what we will call "protective constructs" (i.e., resilience and personal resources), we first discuss literature on the energetic process (which mostly derives from the job demands and resources framework: Demerouti, Bakker, Nachreiner, \& Schaufeli, 2001) in relation to job performance. Secondly, we present some classic personal resources, such as optimism, self-efficacy, and self-regulation, which are likely to be conceived as mediators or moderators in the energetic process. Next, we present the construct of resilience, from an organizational and an individual perspective. Ultimately, we elaborate the "resilience resources" macroconstruct as a protective factor that can interact with exhaustion and job performance.

\section{The energetic process and its relationship with job performance}

When confronted with significantly demanding work conditions, workers tend to adopt performance protection strategies such as reduced performance targets or extra efforts at work (Robert \& Hockey, 1997). Adjustments of performance targets include a reduction of rate and precision in work activities, leaving the maximum energy level at its usual but with costs in terms of performance quality (Schaufeli \& Bakker, 2004; Schaufeli \& Taris, 2014). A second strategy relies on the increment of efforts to face higher job demands. Performance in work tasks is preserved, but only at the cost of an increasing of compensatory effort costs, which can lead to fatigue, exhaustion, or irritability. Although such a strategy may be adaptive in the short run, it is likely to be dysfunctional as a routine and might deplete the individual's energy resulting in burnout. According to Bakker, Demerouti, and Verbeke (2004), both processes might co-occur and are related through an energetic process (i.e., health impairment), where job conditions can determine employees' exhaustion, which in turn affects their well-being and job performance.

This two-stage process is embedded in the job demands and resources (JD-R) model (Demerouti et al., 2001) and has been widely empirically supported (Bakker et al., 2010; Bakker \& Demerouti, 2007; Bakker et al., 2004; Demerouti \& Bakker, 2011; Hakanen et al., 2008; Schaufeli \& Taris, 2014; Xanthopoulou, 
Bakker, Demerouti, \& Schaufeli, 2007). The literature in organizational psychology includes several studies where the energetic process is associated with negative outcomes such as absence duration, counterproductive work behavior, health issues, or worse performance in job tasks (Bakker et al., 2004; Bakker, Van Emmerik, \& Van Riet, 2008; Idris, Dollard, Coward, \& Dormann, 2012). The nature of this relationship depends on the types of job demands, as well as on the outcomes considered, resulting in a partial or full mediation through burnout or its components (e.g., exhaustion). Although job demands are usually negatively related to health outcomes through a negative mediation with burnout (i.e., high job demands lead to burnout, which decreases health), some job demands (e.g., cognitive demands, emotional demands, workload) are also positively and directly associated with task performance, defined as those behaviors that serve the organization aims (Borman \& Motowidlo, 1997). For example, Bakker et al. (2004) found that task performance was mostly predicted by job demands, whereas through workers' exhaustion the relation changes, such that exhaustion appears to negatively mediate the relationship.

Because of the primary importance given to work conditions as principal determinants of well-being and job performance (e.g., the energetic process of the JD-R model) an important extension of such a model has subsequently been developed that also includes personal resources (i.e., self-efficacy, organizational-based self-esteem: [OBSE] and optimism) in predicting exhaustion and work engagement (Xanthopoulou et al., 2007). Personal resources were found to be significant mediators of the processes postulated by the JD-R model, suggesting that classic job resources foster the development of personal resources. Against this background, the next section introduces the most relevant studies regarding personal resources in relation to the components of the energetic process and resilience.

\section{Personal resources as protective factors}

Employees' personal resources, such as self-regulation, self-efficacy and optimism, contribute to develop a better mastery of job conditions and protect them from stress-related aspects (Xanthopoulou et al., 2009). Studies have demonstrated that personal resources are not only linked to physical and emotional well-being, but are also associated to psychological characteristics, such as resilience (Chen, Gully, \& Eden, 2001; Pierce \& Gardner, 2004). In burnout recovering, personal resources postcrisis growth is related to resilience and fostered by emotional self-regulation (Fredrickson, 2005). Well-being is induced through reappraisal and emotional self-regulation processes, broaden one's thoughts and actions, and connected to resilience level disposed by the individual.

Personal resources and resilience are often conceived as traits and consequently as positive moderators that determine under which conditions the 
energetic process leads to negative outcomes. In regard to the role of personal resources as moderators, studies have mainly examined the relationship between job characteristics and burnout or its components. For example, Van Yperen and Snijders (2000) demonstrated the moderating role played by self-efficacy in the relationship between job demands and psychological health symptoms. Under stressful work conditions (e.g., high time pressure, workload, and high cognitive demands) these characteristics would be able to reduce workers' perceptions of effort demanded by the job (Buruck, Dörfel, Kugler, \& Brom, 2016; Cheung et al., 2011; Salminen, Mäkikangas, \& Feldt, 2014; Schaufeli et al., 2009). These studies suggest that employees with high levels of personal resources possess a better mastery of themselves, which in turn helps them to manage difficult environmental conditions more efficiently, eventually preventing the emergence of negative outcomes. However, some researchers argue that personal resources may also be mediators of the relationship between environmental factors and performance outcomes, since they can determine the way in which individuals understand and react toward the organizational environment (Gibbons, Blanton, Gerrard, Buunk, \& Eggleston, 2000).

Supporting this notion, research has shown that personal resources can mediate the relationship between relational climate and well-being (Airila et al., 2014). In another study, Luthans, Avolio, Avey, and Norman (2007) demonstrated that a work environment dense of resources activates psychological capital (i.e., positive psychological states of individual development that include optimism, self-efficacy and resilience; Luthans, Youssef, \& Avolio, 2007), which can help achieve organizational targets. This is in line with the conservation of resources theory (i.e., COR; Hobfoll, 1989, 2002, 2011) that suggests that employees working in a resourceful work environment are likely to reinforce their own resilience (Meneghel, Martinez, \& Salanova, 2016). Overall, evidence shows that job and personal resources are reciprocal dimensions because individuals, through training and experience, can make positive evaluations of themselves and understand and create more resourceful work environments (Gilbert, Foulk, \& Bono, 2017). Nevertheless, the role of personal resources and resilience in the relationship between job demands and exhaustion still deserves attention. Although previous studies reported that employees scoring high on optimism and self-efficacy report lower levels of strain in presence of high job demands (Xanthopoulou et al., 2007), it is possible that such personal resources, including resilience, develop in response to high job demands, eventually lowering the level of exhaustion, which suggests a mediation pattern. In other words, personal resources can not only contribute to achieve a positive environment, but also determine the way in which people perceive, react, and cocreate the work environment. 


\section{Resilience applied to organizations}

In the organizational field, the construct of resilience has generated new interest as a consequence of events, such as the recent financial crisis, which put to the test many organizations and their employees (Cooper, Liu, \& Tarba, 2014; Orchiston et al., 2016; Ortiz-de-Mandojana \& Bansal, 2015). Organizational resilience is defined as the capacity of an organization to absorb the shocks caused by unexpected events, to promptly develop specific responses, and, finally, through experience, to take advantage of the reactions to those shattering events that potentially threaten the survival of the organization (Limnios et al., 2014). The capacity to use resilience when facing adverse events consists of a set of characteristics held by employees that are part of and constitute the organization. Such a conglomerate of abilities and capabilities permits the individuals to promptly direct their action, going beyond the potentially debilitating consequences of negative events. For this reason, the Human Resources (HR) departments of some organizations are focusing their attention on the development of knowledge, skills and abilities (KSAOs) to foster resilience among workers (Cooper et al., 2014). The goal is to have individuals face unexpected events without falling into exhaustion or burnout, and not to put the organization's survival at risk.

Resilience is an interdisciplinary concept that describes the dynamic development of complex adaptive systems that interact across temporal and spatial scales. Accordingly, different disciplines focus on several aspects of resilience, resulting in diverse but interrelated definitions (Folke, 2006). In clinical settings, the construct refers to the cognitive capacity of preventing psychopathology. It relates to the perception of inner strength that can facilitate a quick recovery after stressful interruptions (Mitamura, Reuman, \& Tugade, 2014). Studies within the workplace have demonstrated that resilience is a significant negative mediator between the effects of job stressors and work-related psychological disorders (Bartone, 2006). Individuals with high levels of resilience adapt their coping strategies and they even turn stressors into opportunities (Steinhardt \& Dolbier, 2008). These studies see resilience as a component of mediated-coping processes aiming at avoiding exhaustion through the interaction with other protective factors. In relation to personal resources for example, resilience has been found to positively correlate to self-efficacy and hardiness (Rutter, 1987). Laschinger, Wong, Cummings, and Grau (2014) found that the constructs that are part of psychological capital (i.e., self-efficacy, optimism, and resilience) significantly and negatively correlate with the components of burnout (i.e., exhaustion), suggesting that individuals with high levels of these characteristics perceive more control over the work environment and can therefore face better job demands (Bandura, 1982). 
Inconsistent results have been found in studies that investigate resilience as a negative moderator of individual differences and the manifestation of stress experiences in the workplace (Jacelon, 1997; McFadden, Campbell, \& Taylor, 2014; Rees, Breen, Cusack, \& Hegney, 2015). In such studies, resilience is conceived more as a trait and less changeable, possibly interacting with individual differences such as age or gender. A meta-analysis of the relationship between age, resilience, and job stress found evidence of a significant and negative relation between job stress and resilience but also nonsignificant moderations of resilience and individual differences (McCann et al., 2013). In a research study conducted among nurses, Garrosa, Rainho, Moreno-Jiménez, and Monteiro (2010) assessed the relationship between job stressors and hardy personality (which includes resilience) and coping resources on burnout dimensions. At a transversal level, personal resources were related to hardy personality and negatively associated with emotional exhaustion, but no evidence has been reported concerning the moderation effect of resilience.

\section{Aims and hypotheses}

In the light of above empirical evidence, there is a need for investigating if some personal resources and resilience can function as a mediator and/or a moderator of the energetic processes. Moreover, another aim of the present research is to explore if environmental work conditions can foster the development of such psychological resources among individuals. In particular, recently Demerouti and Bakker (2011) raised some future challenges in relation to the energetic process:

we propose that employees may be particularly at risk for burnout if confronted with high job demands and low job resources and if their personal resources - such as self-efficacy and optimism - are low. In addition, employees may be particularly engaged in their work and flourish if job demands and job resources are high, and if their personal resources - such as resilience - are high as well. (p. 4)

Demerouti and Bakker's hint is certainly useful to address new research in relation to the energetic process and a construct such as resilience. In other words, it is important to analyze if this resources-development process due to challenging job demands is similar to the one of personal resources in relation to job resources.

As it has already been demonstrated in the case of personal resources in relation to job resources, through the presence of some working experiences, individuals could develop more resilience, self-regulation, and self-efficacy by managing more dynamic and intensive workplaces (Judge et al., 2000). This relationship would be valid also in relation to job demands, which could play an experiential role for the individual, and where employees with high levels of resilience and self-efficacy feel to have more control over the environment 


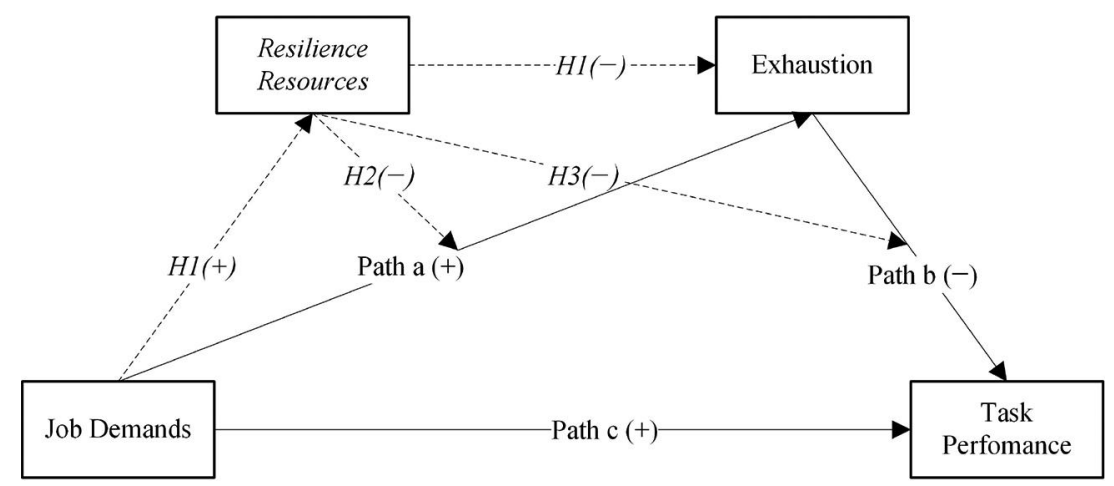

Figure 1. Hypothesized model of the energetic process mediated and/or moderated by resilience resources.

and therefore can manage job demands better (Bandura, 1997). A challenging organizational environment, characterized by a certain kind of job demands (e.g., cognitive demands, emotional demands, workload), may contribute to the development of new strategies by some individuals to cope with those job demands. This is what happens with resilience, which is precisely defined as the capacity of an individual to foster a rapid recovery from traumatic interruptions related to the level of regular mental functioning (McFadden et al., 2014). Individuals with high levels of resilience adapt their coping strategies and often convert stressful factors into learning opportunities, even by ultimately enhancing performance in work tasks (Steinhardt \& Dolbier, 2008).

Considering the present study, our hypotheses can be summarised as follows:

Hypothesis 1:

Resilience and other personal resources (i.e., optimism, emotional self-regulation and self-efficacy; hereafter named "resilience resources") mediate the relationship between job demands (i.e., cognitive demands, emotional demands, workload) and exhaustion (Figure 1), and ultimately between job demands and performance in work tasks.

Hypotheses 2

and 3:

In addition, resilience resources moderate the energetic relationship by protecting employees from exhaustion (H2) and by preserving job performance (H3). All hypothesized relationships are displayed in Figure 1.

\section{Materials and method}

\section{Study population}

Three Italian organizations, of small-medium dimensions, operating in the private service sector, were selected. The involved companies were chosen 
because belonging to a North-East Italian network (territorial sector district) that was economically stressed during and after the 2008 financial crisis. A series of consultations with the HRs of the surveyed companies revealed how in those years such organizations registered a personnel reduction due to the drop of service demand in the market. This changed most of their structural work processes involving employees in adapting to the new conditions. Before starting the survey, the research project has been introduced to those companies that chose to take part to this study. Participants were recruited from the organizations' intranet panel, where they could find an announcement about the research project to be conducted, its scopes, and instructions on how to participate (i.e., pick up a questionnaire at the reception desk, complete, and return it in the attached sealed envelope within the proposed deadline). Participation in the study was voluntary. A total of 208 employees (62\% females) filled in and returned an anonymous questionnaire in a sealed envelope (response rate $80 \%$ ). Their age ranges between 20 and 60 years with an average of 41 years $(S D=9.65)$. At the end of the survey a short report was presented to HRs of companies involved and a discussion about best practices for developing resilience followed.

\section{Materials}

\section{Job demands}

Three job demand items were included in the questionnaire: cognitive demands, emotional demands, and workload. Cognitive demands were evaluated with a 4 -item scale (Bakker et al., 2003). An example item is "Does your work demand enhanced care or precision?" (from $1=$ never to $5=$ always). Workload was evaluated with a 3 -item scale (Bakker et al., 2014): "Do you have too much work to do?" "Do you have to work very fast?" "How often does it occur that you have to work extra hard to finish your work?" Responses were based on a 5-point Likert-type scale (from $1=$ never to $5=$ always). Emotional demands were based on a scale developed by Van Veldhoven and Meijman (1994) and included four items. An example is "Does your work put you in emotional situations?" $(1=$ never, $5=$ always $)$.

\section{Personal resources}

The Personal Resources scale by Bakker (2014) was used in the questionnaire. This 8-item scale comprises four items that measure optimism (e.g., "I am always optimistic about my future") and four items for measuring self-efficacy (e.g., "I am confident that I could deal effectively with unexpected events"). Answers range from 1 (totally disagree) to 5 (totally agree for the optimism items; Self-efficacy was assessed with a four-point scale, ranging from 1 (absolutely wrong) to 4 (absolutely right). The cognitive reappraisal subscale of the Emotion Regulation Questionnaire (ERQ) by Gross and John (2003) 
was used to measure emotional self-regulation. Three items measuring participants' tendency to cognitively change the meaning of emotional experience were selected. Example items are "When I want to feel less negative emotion (such as sadness or anger), I change what I'm thinking about" and "When I want to feel more positive emotion, I change the way I'm thinking about the situation" ( $1=$ strongly disagree, $7=$ strongly agree $)$.

\section{Resilience}

The Dispositional Resilience Scale (DRS-15) by Bartone (2007) and validated in Italian by Picardi et al. (2012) was used to measure resilience. We selected the five items which concern work activities, such as "By working hard you can nearly always achieve your goals" or "I really look forward to my work activities." The rate is expressed on a 4 -point rating scale $(1=$ totally disagree, $4=$ totally agree $)$.

\section{Exhaustion}

Three exhaustion items of the Oldenburg Burnout Inventory (Demerouti \& 390 Bakker, 2008) were used to measure participants' exhaustion. Example items are "There are days when I feel tired before I arrive at work" and "After my work, I usually feel worn out and weary" ( $1=$ totally disagree, $4=$ totally agree).

\section{Task performance}

Job performance was assessed using the task performance scale (i.e., in-role performance of the Individual Work Performance Questionnaire: IWPQ, Koopmans et al., 2012). The scale is composed of five items measuring task performance to be rated on a 5 -point rating scale $(0=$ never, $4=$ very often $)$. An example item is "I managed to plan my work so that it was done on time."

\section{Results}

\section{Descriptive statistics}

Table 1 shows the Means, Standard Deviations, correlations, and the internal consistency indexes of the scales. All scales presented acceptable reliability indexes. All personal resources and resilience measures showed to be correlated together. In relation to sociodemographic variables, resilience showed positive correlations with education $(r=.27, p<.01)$ and with job position $(r=.25, p<.01)$. All personal resources and resilience revealed positive correlations with the number of supervised staff. No correlations were found between personal resources and demographic variables in terms of gender and age. Significant and positive correlations were found between most of the job demands measured and some personal resources and 


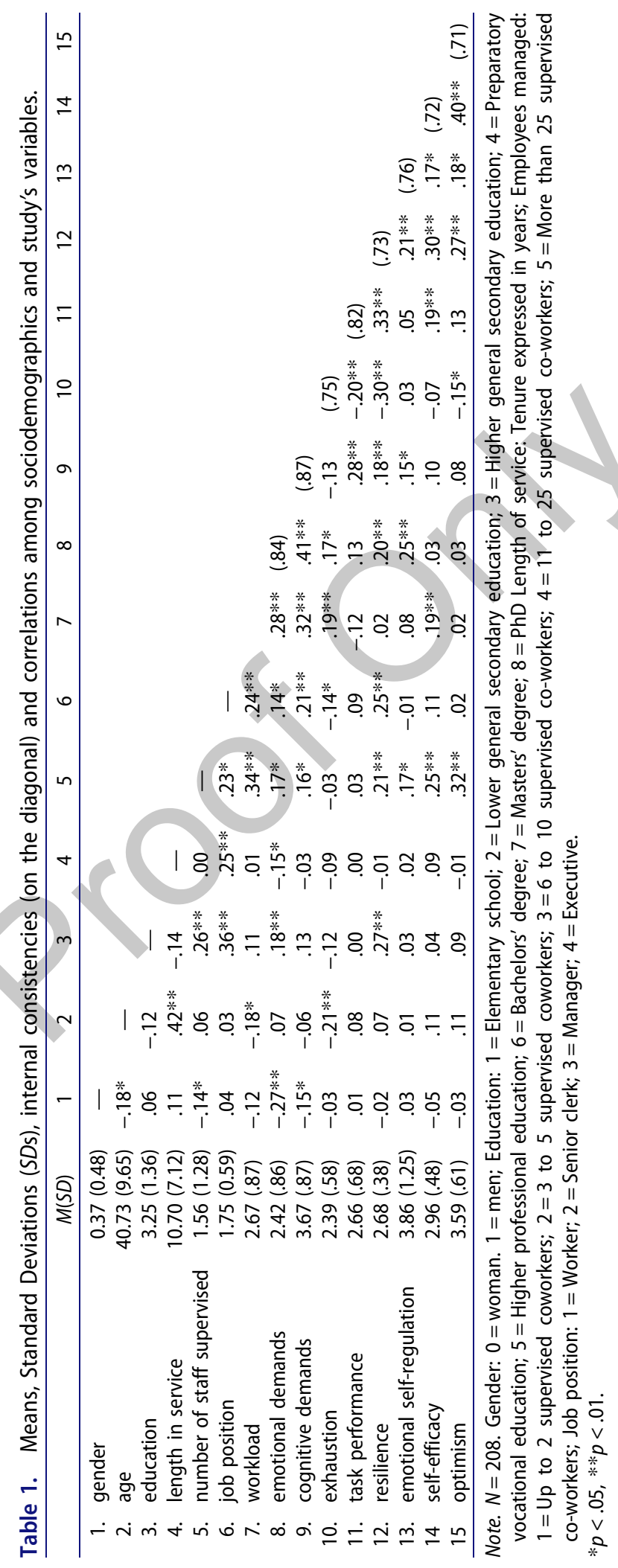


resilience; negative correlations were found with some personal resources and resilience and exhaustion, thereby partially confirming Hypothesis 1 . Additionally, exhaustion showed a negative correlation with task performance $(r=-.20, p<.01)$, which is in line with literature on the energetic process.

\section{Hypotheses testing}

Following the statistical procedure suggested by Hayes (2013), to verify H1, we tested for the presence of a (partial or full) mediation model based on the energetic process in relation to resilience and personal resources. Before proceeding with the modeling of the mediation, we first tested if job demands (i.e., cognitive demands, emotional demands, workload) are predictors of resilience, optimism, emotional self-regulation, and self-efficacy. The single regression analyses (see Table 2) revealed that workload positively and significantly predicted self-efficacy. Additionally, resilience and emotional self-regulation were predicted by cognitive and emotional demands; optimism instead was not predicted by any job demands. Secondly, aggregate scores of each single component were computed. The resilience resources score comprised resilience, emotional self-regulation, and self-efficacy components, which all are related to job demands. We first tested the reliability of the aggregate resilience resource score, by carrying out two CFAs: one on the three constructs (i.e., resilience, emotional self-regulation and self-efficacy components) and a second one by using a bifactor analysis (i.e., resilience resource) to investigate the goodness of fit for a single indicator. The first CFA shows adequate fit indexes: $\chi^{2}(32)=46.510(p<.01)$, Comparative Fit Index $(\mathrm{CFI})=.954$, Tucker-Lewis Index $(\mathrm{TLI})=.922$, root mean square error of approximation (RMSEA) $=.047$. However, one item of the self-esteem scale showed very strong correlations with the others (likely due to its wording that emphasizes self-esteem in the workplace), and a particularly strong correlation with another self-esteem item. In the present context, these items might be perceived as almost collinear. With such a covariation modeled, the indexes of fit improved: $\chi^{2}(31)=42.413(p=.083), \mathrm{CFI}=.964$, TLI $=.936$, $\mathrm{RMSEA}=.042$. Finally, through a bifactor model we verified the presence

Table 2. Regression analyses of mediation effects of job demands on resilience and personal resources.

\begin{tabular}{|c|c|c|c|c|c|c|c|c|}
\hline \multirow[b]{2}{*}{ Predictors } & \multicolumn{2}{|c|}{ Resilience } & \multicolumn{2}{|c|}{ Self-efficacy } & \multicolumn{2}{|c|}{ Optimism } & \multicolumn{2}{|c|}{ Emotion regulation } \\
\hline & $\beta$ & $R^{2}$ & $\beta$ & $R^{2}$ & $\beta$ & $R^{2}$ & $\beta$ & $R^{2}$ \\
\hline Workload & -.01 & & $.20 * *$ & & .02 & & .08 & \\
\hline & & .00 & & $.04 * *$ & & .00 & & .01 \\
\hline Emotional demands & $.20 * *$ & $.04 * *$ & .03 & .01 & .03 & .01 & $.25 * *$ & $.06 * *$ \\
\hline Cognitive demands & $.18^{* *}$ & $.03^{* *}$ & .10 & .01 & .01 & .01 & $.15 * *$ & $.02 *$ \\
\hline
\end{tabular}


of an underlying single indicator (i.e., resilience resource), $\chi^{2}(23)=27.074$ $(p=.253), \mathrm{CFI}=.976$, TLI $=.969, \mathrm{RMSEA}=.029$. Then, we mean-centered and used bootstrapping following the PROCESS procedure recommended by Hayes (2013). The results confirmed a double mediation model, $R^{2}=.107$, $p<.001, \quad F(204 ; 1)=8.161$, in the presumed direction, where, except for the main effect, the single mediated relationships were all significant (job demands $\rightarrow$ task performance: $t=1.299, p=.20$; resilience resources $->$ exhaustion: $t=-3.186, p<.001$; exhaustion $\rightarrow$ task performance $t=-2.541, p<.01)$. The analysis of the total effect was not significant $95 \%$ confidence interval (CI) $[-.019,721]$, whereas all the indirect effects were job demands $\rightarrow$ resilience resources $->$ task performance: 95\% CI [.045, 329]; job demands $\rightarrow$ resilience resources $\rightarrow$ exhaustion $\rightarrow$ task performance: 95\% CI $[.005,086]$; job demands $->$ exhaustion $\rightarrow$ task performance: $95 \%$ CI $[-.214,-.008]$. Note that even if the total effect was not significant, it is legitimate to conclude that resilience resources and exhaustion mediates the association between job demands and task performance for two reasons. First, there is a relatively large consensus among statisticians that the total effect should not be used as a "gatekeeper" for testing mediations (e.g., Hayes, 2009; Shrout \& Bolger, 2002). The second reason consists in the particularity of such a double mediation, where the indirect effect of job demands on task performance is positive, whereas the indirect effect through second mediator (i.e., exhaustion) is negative, and the simultaneous presence of the two indirect effects with opposite signs is proved to nullify the total effect.

Considering $\mathrm{H} 2$ and $\mathrm{H} 3$, moderation effects of resilience resources were tested on the classic relationships of the energetic process. Particularly, between job demands and exhaustion (Path a: H2), and between exhaustion and task performance (Path b: H3) by using two singular mediation-moderation models as suggested by Hayes (2013). Results confirmed no significant moderation effect due to resilience resources in each analysis, except for Path $b$ (exhaustion $->$ task performance) which was close to the significance level, Path a: job demands $\times$ resilience resources $->$ task performance: $\mathrm{B}=-.062(.64), p=.93$; Path $\mathrm{b}$ : exhaustion $\times$ resilience resources $\rightarrow$ task performance: $B=-.201(.34), p=.06$.

\section{Discussion}

This study aimed at investigating whether resilience and other personal resources (i.e., optimism, emotional self-regulation, and self-efficacy), can be defined as an unique macroconstruct, called resilience resources, which can mediate the relationship between job demands (i.e., cognitive demands, emotional demands, workload) and exhaustion, as well as task performance. The study also shed light on the moderating role of such a component in the energetic process postulated by the JD-R model, investigating how 
resilience resources protect employees from exhaustion eventually preserving 485 task performance.

Results showed the statistical reliability of the unique indicator of resilience resources, composed of resilience, emotional self-regulation, and self-efficacy, all positively tied to job demands, except for optimism. Even though optimism is negatively related to exhaustion, it cannot be considered as a possible mediator because it showed no significant relationships with job demands. Results supported the first hypothesis concerning the presence of a full mediation between job demands, resilience resources, exhaustion, and task performance. Thus, resilience resources could be considered as a psychological shield because they are positively associated with job demands and negatively to exhaustion. No moderation effects were found in relation to resilience or any other of the personal resources considered, providing no support for Hypotheses 2 and 3, which is partially in line with previous literature (King, Newman, \& Luthans, 2015; Lü, Wang, Liu, \& Zhang, 2014). Figure 2 graphically represents the relationships confirmed by the analyses.

This study demonstrates that the mediated relationship between personal resources and classic job resources (Xanthopoulou et al., 2007; Xanthopoulou et al., 2009a, 2009b) can be valid also for so-called resilience resources in the energetic process. Through working experiences, individuals can develop more resilience, self-efficacy, and learn self-regulation coping strategies to deal with high job demands and by avoiding exhaustion. In other words, an intensive and challenging work environment, characterized by certain kinds of job demands (i.e., workload, cognitive demands, emotional demands), may contribute to the development of strategies by some individuals to cope with job demands and preserving performance.

For this reason it is important to mention that job demands need not to be necessarily considered as negative, and they still are an indirect index of

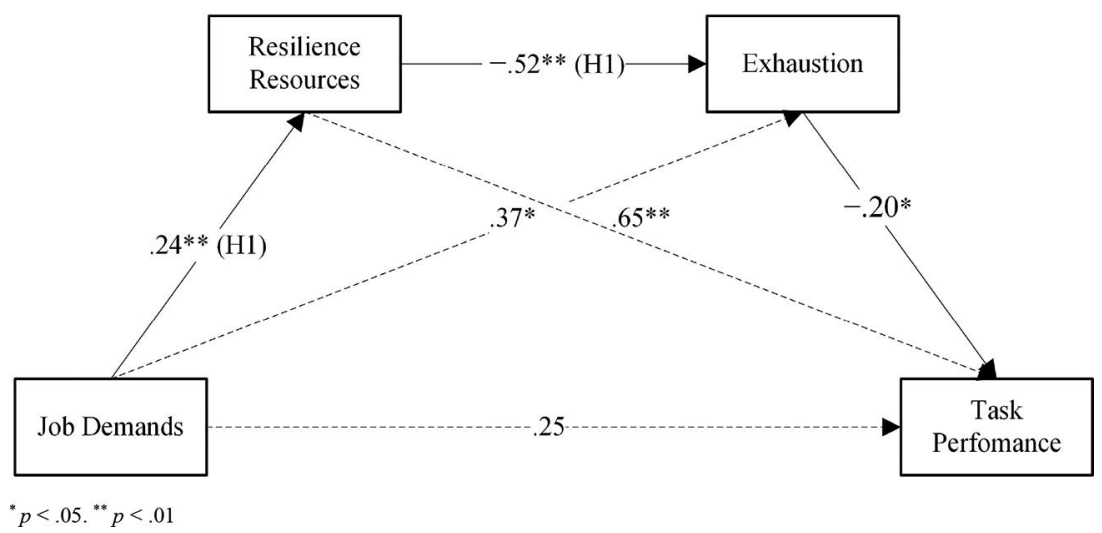

Figure 2. Confirmed model with standardized coefficient of the energetic process mediated by resilience resources. 
productivity (if not particularly high) and of performance related to the task (Bakker \& Demerouti, 2007). Resilience, self-regulation, and self-efficacy can therefore positively influence the health impairment process by mediating the relationship between job demands and exhaustion. The presence of these relationships can be explained by the environment's capability of influencing the psychological constructs investigated here. However, it is also possible that individuals with higher levels of resilience are better fit for the organizational environment and retained through self-selection.

Employees with high levels of self-efficacy feel they have more control over the environment and can therefore manage high workloads better (Bandura, 1997). Emotional self-regulation, and in particular cognitive reappraisal, which involves reframing a situation to change its emotional impact, help in this situation (Mauss, Bunge, \& Gross, 2007). This strategy seems to be functional in relation to emotional demands. The present study shows that resilience and its relationship with cognitive and emotional demands mediates between job demands and exhaustion. In this framework, resilient employees are those who are able to implement coping strategies, such as being focused on the problem, the capacity to take time before acting, and to give and receive support from one's own workmates (Bartone, 2006). Actions aimed at helping individuals protect themselves in stressful situations, as well as at restoring their functional state quickly, seem to be best for organizations and their workforce. Individuals with high levels of resilience adapt their coping strategies and frequently transform stressful aspects into learning chances (Steinhardt \& Dolbier, 2008).

\section{Limitations and future research}

Although this study provided support for the proposed mediation, results may be qualified by potential limitations. First, in common with several I/O studies, the present research lacks an objective measure of task performance (Spector, 2006) and no longitudinal data were used to measure it. A second potential limitation is related to the causal antecedents for the development of resilience and personal resources in employees. Evidence from longitudinal studies in the work stress area has shown that organizational demands have no immediate consequences on outcomes such as exhaustion (Xanthopoulou et al., 2009). Moreover, we have to consider that the mediation could not be found in relation to more detrimental types of job demands, such as role conflict or workplace hassles. Further analyses may confirm if such relationships are determined by individual differences related to the mediators and antecedents here considered. Future studies could also include classic job resources (e.g., feedback, organizational support, career opportunities, autonomy, etc.) to test classic JD-R relationships together with resilience resources. The relationship between resilience, job position, and number of 
staff supervised also deserves further attention, as these are associated to roles that imply responsibility and more stress.

Finally, future research looking for replicability of present findings should also consider using a sample of the worker population other than service companies, considering also careers particularly prone to exhaustion. Moderation due to resilience resources among the relationship between exhaustion should be tested again, because effects found were close to the significance level.

\section{Conclusion and practical implications}

The word crisis originates from the Greek word krisis which means "decisive moment." In the organizational field, economic crises put significant strain on companies and their employees and at the same time generate interest in the role that resilience plays in offsetting such crises (Cooper et al., 2014; Orchiston et al., 2016; Ortiz-de-Mandojana \& Bansal, 2015). For many companies, such times have been a decisive one-way movement forward, especially in assessing and retaining employees' resilience. A direct practical implication of the current research is the interesting and ethical question whether organizations should hire only resilient employees. In that sense, it is important to mention that this psychological shield based on resilience resources seems to be generated by work experience. Even if such a competence could be reliably detectable, these psychological characteristics highly depend on the opportunities given by the work environment. Thus, resilience can be considered as a developable competence rather than a personal trait. This is also in line with the findings of the present study, which show no correlation of resilience and personal resources with individual differences indicators (i.e., age, gender). Instead, several correlations have been found in relation to education level, job position and number of staff supervised, giving credence to the idea that resilience resources are trainable and covary with the role of work environment.

In light of such evidence, an assessment designed to detect highly resilient workers might not be enough to indicate who is "tough enough" when the next economic crisis comes around. Therefore, considering resilience as a competence, a better investment for a company would rely more on training programs. For instance, based on the development of knowledge, skills and abilities to foster resilience among workers, the KSAOs program could be a more efficient HR strategy than an assessment designed for detecting resilience qualities (Cooper et al., 2014). The compound KSAOs program is intended to enhance competing forces required to achieve organizational resilience. To support the development of resilience, the program leverages several behavioral and organizational aspects, such as encourage worker flexibility, boost problem solving, develop facilitative communication 
processes, activate reflective thinking, develop awareness on repetitive strategies applied to response to previous burnout threats. Other training programs resilience oriented come from the established literature on recovery and techniques that help workers to recuperate quickly from stressors. As for resilience training, recovery interventions are based on specific modules, such as: improving psychological detachment from work, control of off-job time and mastering work stressful experiences (Hahn, Binnewies, Sonnentag, \& Mojza, 2011).

Together with training courses, another possibility relates with Employee Assistance Programs (EAPs) that deliver counselling services that focus on prevention and remediation toward destructive processes experienced across the workplace. The core service offered by an EAP is based on brief interventions for behavioral health conditions directed at work-life-related problems that can critically affect job performance and worker health (Kirk \& Brown, 2003).

Considering that these interventions act at the individual rather than at the organizational level, they might be particularly relevant for a bottom-upresilience enhancement. Contemporary EAPs deliver services off site through specialized networks of managed behavioral health care organizations. Services offered by these EAP networks include providing information of psychological counseling, conducting mental health educational sessions at the worksite, sessions of critical incident stress and trauma debriefing, wellness and preventing exhaustion programs. These interventions move overall the entire organization toward more well-being and positive psychological states by boosting recovery and resilience in employees (Hahn et al., 2011).

On the other hand, all the programs here presented might be criticized by the reader because of the difficult applicability during crisis times, especially because of lack of budget. Based on our experience, because we have observed the reactions of the HRs involved during the presentation of the current research study, even the simple introduction to the concept of resilience spread the awareness of the construct itself in organizations. Feedbacks derived from survey reports showed us how the construct of resilience was often confused by HRs with the concept of "psychological resistance." This distinction has been clarified by presenting some classical definitions of both constructs and by stressing how the resistance culture of "keep going" needed to leave the room to some evidence-based good practices for the development of organizational resilience. In other words, organizations instead of just keep repeating to employees to "resist during stressful times, should promote a shared acceptance of workforce limits by instilling the awareness that rough time are momentary. Therefore, the expectations of companies toward them should be directed to coping stress management strategies for a quickly and fully remediation from harsh work conditions. 


\section{Acknowledgments}

The present research study was designed with multiple research purposes and approved by the Ethical Review Committee at the University of Verona. The authors are grateful to the University of Trento and Italian trade unions CILS, CGIL and UIL for the recognizment as one of the best research studies in labor sector.

\section{ORCID}

Andrea Ceschi (D) http://orcid.org/0000-0001-9059-9237

\section{References}

Ablett, J. R., \& Jones, R. (2007). Resilience and well-being in palliative care staff: A qualitative study of hospice nurses' experience of work. Psycho-Oncology, 16(8), 733-740. doi:10.1002/ pon. 1130

Airila, A., Hakanen, J. J., Schaufeli, W. B., Luukkonen, R., Punakallio, A., \& Lusa, S. (2014). Are job and personal resources associated with work ability 10 years later? The mediating role of work engagement. Work \& Stress, 28, 87-105. doi:10.1080/ 02678373.2013 .872208

Bakker, A. B. (2014). The job demands-resources questionnaire. Rotterdam, The Netherlands: Erasmus University Press.

Bakker, A. B., Boyd, C. M., Dollard, M., Gillespie, N., Winefield, A. H., \& Stough, C. (2010). The role of personality in the job demands-resources model: A study of Australian academic staff. Career Development International, 15(7), 622-636. doi:10.1108/13620431011094050

Bakker, A. B., \& Demerouti, E. (2007). The job demands-resources model: State of the art. Journal of Managerial Psychology, 22(3), 309-328. doi:10.1108/02683940710733115

Bakker, A. B., \& Demerouti, E. (2014). Job demands-resources theory. In P. Y. Chen \& C. L. Cooper (Eds.), Work and wellbeing: Wellbeing: A complete reference guide (Vol. III, pp. 1-28). Hoboken, NJ: John Wiley \& Sons.

Bakker, A. B., Demerouti, E., Taris, T. W., Schaufeli, W. B., \& Schreurs, P. J. (2003). A multigroup analysis of the job demands-resources model in four home care organizations. International Journal of Stress Management, 10(1), 16-38. doi:10.1037/1072-5245.10.1.16

Bakker, A. B., Demerouti, E., \& Verbeke, W. (2004). Using the job demands-resources model to predict burnout and performance. Human Resource Management, 43(1), 83-104. doi:10.1002/hrm.20004

Bakker, A. B., Van Emmerik, H., \& Van Riet, P. (2008). How job demands, resources, and burnout predict objective performance: A constructive replication. Anxiety, Stress, \& Coping, 21(3), 309-324. doi:10.1080/10615800801958637

Balducci, C., Schaufeli, W. B., \& Fraccaroli, F. (2011). The job demands-resources model and counterproductive work behaviour: The role of job-related affect. European Journal of Work and Organizational Psychology, 20(4), 467-496. doi:10.1080/13594321003669061

Bandura, A. (1982). Self-efficacy mechanism in human agency. American Psychologist, 37(2), 122-147. doi:10.1037/0003-066X.37.2.122

Bandura, A. (1997). Self-efficacy: The exercise of control. New York, NY: W. H. Freeman.

Bartone, P. T. (2006). Resilience under military operational stress: Can leaders influence hardiness? Military Psychology, 18, 131-148. doi:10.1207/s15327876mp1803s_10

Bartone, P. T. (2007). Test-retest reliability of the dispositional resilience scale-15, a brief hardiness scale. Psychological Reports, 101(3), 943-944. doi:10.2466/pr0.101.3.943-944 
Borman, W. C., \& Motowidlo, S. J. (1997). Task performance and contextual performance: The meaning for personnel selection research. Human Performance, 10(2), 99-109. doi:10.1207/s15327043hup1002_3

Brauchli, R., Schaufeli, W. B., Jenny, G. J., Füllemann, D., \& Bauer, G. F. (2013). Disentangling stability and change in job resources, job demands, and employee well-being -A three-wave study on the job-demands resources model. Journal of Vocational Behavior, 83(2), 117-129. doi:10.1016/j.jvb.2013.03.003

Buruck, G., Dörfel, D., Kugler, J., \& Brom, S. S. (2016). Enhancing well-being at work: The role of emotion regulation skills as personal resources. Journal of Occupational Health Psychology, 21(4), 480. doi:10.1037/a0025787

Chen, G., Gully, S. M., \& Eden, D. (2001). Validation of a new general self-efficacy scale. Organizational Research Methods, 4, 62-83. doi:10.1177/109442810141004

Cheung, F., Tang, C. S.-K., \& Tang, S. (2011). Psychological capital as a moderator between emotional labor, burnout, and job satisfaction among school teachers in China. International Journal of Stress Management, 18(4), 348. doi:10.1037/a0025787

Chodorow-Reich, G. (2014). The employment effects of credit market disruptions: Firm-level evidence from the 2008-9 financial crisis. Quarterly Journal of Economics, 129(1), 1-59. doi:10.1093/qje/qjt031

Cooper, C. L., Liu, Y., \& Tarba, S. Y. (2014). Resilience, HRM practices and impact on organizational performance and employee well-being. International Journal of Human Resource Management, 25(17), 2466-2471. doi:10.1080/09585192.2014.926688

Demerouti, E., \& Bakker, A. B. (2008). The Oldenburg Burnout Inventory: A good alternative to measure burnout and engagement. In (Ed.), Handbook of stress and burnout in health care (pp.). Hauppauge, NY: Nova Science.

Demerouti, E., \& Bakker, A. B. (2011). The job demands-resources model: Challenges for future research. SA Journal of Industrial Psychology, 37(2), 01-09. doi:10.4102/sajip. v37i2.974

Demerouti, E., Bakker, A. B., Nachreiner, F., \& Schaufeli, W. B. (2001). The job demandsresources model of burnout. Journal of Applied Psychology, 86(3), 499-512. doi:10.1037/ 0021-9010.86.3.499

Folke, C. (2006). Resilience: The emergence of a perspective for social-ecological systems analyses. Global Environmental Change, 16(3), 253-267. doi:10.1016/j. gloenvcha.2006.04.002

Fredrickson, B. L. (2005). The broaden-and-build theory of positive emotions. In F. A. Huppert, N. Baylis, \& B. Keverene (Eds.), The science of well-being (pp. 217-318). New York, NY: Oxford University Press.

Garrosa, E., Rainho, C., Moreno-Jiménez, B., \& Monteiro, M. J. (2010). The relationship between job stressors, hardy personality, coping resources and burnout in a sample of nurses: A correlational study at two time points. International Journal of Nursing Studies, 47(2), 205-215. doi:10.1016/j.ijnurstu.2009.05.014

Gibbons, F. X., Blanton, H., Gerrard, M., Buunk, B., \& Eggleston, T. (2000). Does social comparison make a difference? Optimism as a moderator of the relation between comparison level and academic performance. Personality and Social Psychology Bulletin, 26(5), 637-648. doi:10.1177/0146167200267011

Gilbert, E., Foulk, T., \& Bono, J. (2017). Building personal resources through interventions: An integrative review. Journal of Organizational Behavior, 1-15. doi:10.1002/ job. 2198

Gross, J. J., \& John, O. P. (2003). Individual differences in two emotion regulation processes: Implications for affect, relationships, and well-being. Journal of Personality and Social Psychology, 85(2), 348-362. doi:10.1037/0022-3514.85.2.348 
Hahn, V. C., Binnewies, C., Sonnentag, S., \& Mojza, E. J. (2011). Learning how to recover from job stress: Effects of a recovery training program on recovery, recovery-related self-efficacy, and well-being. Journal of Occupational Health Psychology, 16(2), 202-216. doi:10.1080/ 02678370802379432

Hakanen, J. J., Bakker, A. B., \& Schaufeli, W. B. (2006). Burnout and work engagement among teachers. Journal of School Psychology, 43(6), 495-513. doi:10.1016/j.jsp.2005.11.001

Hakanen, J. J., Schaufeli, W. B., \& Ahola, K. (2008). The job demands-resources model: A three-year cross-lagged study of burnout, depression, commitment, and work engagement. Work \& Stress, 22(3), 224-241.

Hayes, A. F. (2009). Beyond Baron and Kenny: Statistical mediation analysis in the new millennium. Communication Monographs, 76(4), 408-420. doi:10.1080/03637750903310360

Hayes, A. F. (2013). Introduction to mediation, moderation, and conditional process analysis: A regression-based approach. New York, NY: Guilford Press

Ho, M., Teo, S. T., Bentley, T., Verreyne, M.-L., \& Galvin, P. (2014). Organizational resilience and the challenge for human resource management: Conceptualizations and frameworks for theory and practice. Paper presented at the International Conference on Human Resource Management and Professional Development for the Digital Age (HRM\&PD) Proceedings.

Idris, M. A., Dollard, M. F., Coward, J., \& Dormann, C. (2012). Psychosocial safety climate: Conceptual distinctiveness and effect on job demands and worker psychological health. Safety Science, 50(1), 19-28. doi:10.1016/j.ssci.2011.06.005

Jacelon, C. S. (1997). The trait and process of resilience. Journal of Advanced Nursing, 25(1), 123-129. doi:10.1046/j.1365-2648.1997.1997025123.x

King, D. D., Newman, A., \& Luthans, F. (2016). Not if, but when we need resilience in the workplace. Journal of Organizational Behavior, 37(5), 782-786. doi:10.1002/job.2063

Koopmans, L., Bernaards, C., Hildebrandt, V., van Buuren, S., van der Beek, A. J., \& de Vet, H. C. (2012). Development of an individual work performance questionnaire. International Journal of Productivity and Performance Management, 62(1), 6-28. doi:10.1108/ 17410401311285273

Kirk, A. K., \& Brown, D. F. (2003). Employee assistance programs: A review of the management of stress and wellbeing through workplace counselling and consulting. Australian Psychologist, 38(2), 138-143.

Laschinger, H. K. S., \& Fida, R. (2014). New nurses burnout and workplace wellbeing: The influence of authentic leadership and psychological capital. Burnout Research, 1(1), 19-28.

Limnios, E. A. M., Mazzarol, T., Ghadouani, A., \& Schilizzi, S. G. (2014). The resilience architecture framework: Four organizational archetypes. European Management Journal, 32(1), 104-116. doi:10.1016/j.emj.2012.11.007

Lorens, S., Bakker, A. B., Schaufeli, W., \& Salanova, M. (2006). Testing the robustness of the job demands-resources model. International Journal of Stress Management, 13(3), 378-391. doi:10.1037/1072-5245.13.3.378

Lü, W., Wang, Z., Liu, Y., \& Zhang, H. (2014). Resilience as a mediator between extraversion, neuroticism and happiness, PA and NA. Personality and Individual Differences, 63, 128-133. doi:10.1016/j.paid.2014.01.015

Luthans, F., Avolio, B. J., Avey, J. B., \& Norman, S. M. (2007). Positive psychological capital: Measurement and relationship with performance and satisfaction. Personnel Psychology, 60(3), 541-572. doi:10.1111/j.1744-6570.2007.00083.x

Mauss, I. B., Bunge, S. A., \& Gross, J. J. (2007). Automatic emotion regulation. Social and Personality Psychology Compass, 1(1), 146-167. doi:10.1111/j.1751-9004.2007.00005

McCann, C. M., Beddoe, E., McCormick, K., Huggard, P., Kedge, S., Adamson, C., \& Huggard, J. (2013). Resilience in the health professions: A review of recent literature. International Journal of Wellbeing, 3(1), 60-81. doi:10.5502/ijw.v3i1.4 
McFadden, P., Campbell, A., \& Taylor, B. (2014). Resilience and burnout in child protection social work: Individual and organisational themes from a systematic literature review. British Journal of Social Work, 45(5), 1546-1563. doi:10.1093/bjsw/bct210

Meneghel, I., Salanova, M., \& Martínez, I. M. (2016). Feeling good makes us stronger: How team resilience mediates the effect of positive emotions on team performance. Journal of Happiness Studies, 17(1), 239-255. doi:10.1007/s10902-014-9592-6

Merrick, E. S., Volpe-Vartanian, J., Horgan, C. M., \& McCann, B. (2007). Revisiting Employee Assistance Programs and substance use problems in the workplace: Key issues and a research agenda. Psychiatric Services, 58(10), 1262-1264. doi:10.1176/appi.ps.58.10.1262

Meyers, M. C., van Woerkom, M., \& Bakker, A. B. (2013). The added value of the positive: A literature review of positive psychology interventions in organizations. European Journal of Work and Organizational Psychology, 22, 618-632. doi:10.1080/1359432X.2012.694689

Mitamura, C., Reuman, L., \& Tugade, M. (2014). Resilience. In Encyclopedia of quality of life and well-being research (pp. 5529-5531). Netherlands: Springer.

Nahrgang, J. D., Morgeson, F. P., \& Hofmann, D. A. (2011). Safety at work: A meta-analytic investigation of the link between job demands, job resources, burnout, engagement, and safety outcomes. Journal of Applied Psychology, 96(1), 71-94. doi:10.1037/a0021484

Orchiston, C., Prayag, G., \& Brown, C. (2016). Organizational resilience in the tourism sector. Annals of Tourism Research, 56, 145-148. doi:10.1016/j.annals.2015.11.002

Ortiz-de-Mandojana, N., \& Bansal, P. (2016). The long-term benefits of organizational resilience through sustainable business practices. Strategic Management Journal, 37(8), 1615-1631. doi:10.1002/smj.2410

Picardi, A., Bartone, P. T., Querci, R., Bitetti, D., Tarsitani, L., Roselli, V., ... Gaviano, I. (2012). Development and validation of the Italian version of the 15-item Dispositional Resilience Scale. Rivista di Psichiatria, 47(3), 231-237. doi:10.1708/1128.12446

Pierce, J. L., \& Gardner, D. G. (2004). Self-esteem within the work and organizational context: A review of the organization-based self-esteem literature. Journal of Management, 30(5), 591-622. doi:10.1016/j.jm.2003.10.001

Rees, C. S., Breen, L. J., Cusack, L., \& Hegney, D. (2015). Understanding individual resilience in the workplace: The international collaboration of workforce resilience model. Frontiers in Psychology, 6, 73. doi:10.3389/fpsyg.2015.00073

Robert, G., \& Hockey, J. (1997). Compensatory control in the regulation of human performance under stress and high workload: A cognitive-energetical framework. Biological Psychology, 45(1), 73-93. doi:10.1016/S0301-0511(96)05223-4

Rutter, M. (1987). Psychosocial resilience and protective mechanisms. American Journal of Orthopsychiatry, 57(3), 316-331. doi:10.1111/j.1939-0025.1987.tb03541.x

Salminen, S., Mäkikangas, A., \& Feldt, T. (2014). Job resources and work engagement: Optimism as moderator among Finnish managers. Journal of European Psychology Students, 5(1), 69-77. doi:10.5334/jeps.bu

Schaufeli, W. B., \& Bakker, A. B. (2004). Job demands, job resources, and their relationship with burnout and engagement: A multi-sample study. Journal of Organizational Behavior, 25(3), 293-315. doi:10.1002/job.248

Schaufeli, W. B., Bakker, A. B., \& Van Rhenen, W. (2009). How changes in job demands and resources predict burnout, work engagement, and sickness absenteeism. Journal of Organizational Behavior, 30 (7), 893-917. doi:10.1002/job.595

Schaufeli, W. B., \& Taris, T. W. (2014). A critical review of the Job Demands-Resources Model: Implications for improving work and health. Bridging Occupational, Organizational and Public Health, 43-68. doi:10.1007/978-94-007-5640-3_4

Shiller, R. J. (2012). The subprime solution: How today's global financial crisis happened, and what to do about it. Princeton University Press. 
Shrout, P., \& Bolger, N. (2002). Mediation in experimental and nonexperimental studies: New procedures and recommendations. Psychological Methods, 7, 422-445. doi:10.1037//1082989x.7.4.422

Spector, P. E. (2006). Method variance in organizational research truth or urban legend? Organizational Research Methods, 9(2), 221-232. doi:10.1177/1094428105284955

Steinhardt, M., \& Dolbier, C. (2008). Evaluation of a resilience intervention to enhance coping strategies and protective factors and decrease symptomatology. Journal of American College Health, 56(4), 445-453. doi:10.3200/jach.56.44.445-454

Van den Heuvel, M., Demerouti, E., Bakker, A. B., Schaufeli, W. B., Houdmont, J., \& Leka, S. (2010). Personal resources and work engagement in the face of change. Contemporary Occupational Health Psychology: Global Perspectives on Research and Practice, 1, 124-150.

Xanthopoulou, D., Bakker, A. B., Demerouti, E., \& Schaufeli, W. B. (2007). The role of personal resources in the job demands-resources model. International Journal of Stress Management, 14(2), 121-141. doi:10.1037/1072-5245.14.2.121

Xanthopoulou, D., Bakker, A. B., Demerouti, E., \& Schaufeli, W. B. (2009a). Reciprocal relationships between job resources, personal resources, and work engagement. Journal of Vocational Behavior, 74(3), 235-244. doi:10.1016/j.jvb.2008.11.003

Xanthopoulou, D., Bakker, A. B., Demerouti, E., \& Schaufeli, W. B. (2009b). Work engagement and financial returns: A diary study on the role of job and personal resources. Journal of Occupational and Organizational Psychology, 82(1), 183-200. doi:10.1348/ $096317908 \times 285633$

Youssef, C. M., \& Luthans, F. (2005). Resiliency development of organizations, leaders and employees: Multi-level theory building for sustained performance. Authentic Leadership Theory and Practice: Origins, Effects and Development, 3, 303-343. 